\title{
Biased Managers as Strategic Commitment in a Mixed Duopoly
}

\author{
Yasuhiko Nakamura \\ College of Economics, Nihon University, Tokyo, Japan \\ Email: yasuhiko.r.nakamura@gmail.com
}

Received 21 October 2014; revised 30 November 2014; accepted 15 December 2014

Copyright (C) 2014 by author and Scientific Research Publishing Inc.

This work is licensed under the Creative Commons Attribution International License (CC BY). http://creativecommons.org/licenses/by/4.0/

(c) (i) Open Access

\section{Abstract}

This paper analyzes a model in which both the owner of a social welfare-maximizing public firm and the owner of an absolute profit-maximizing private firm can hire biased managers for strategic reasons in a mixed duopoly in the contexts of both a price competition and a quantity competition. In this paper, in a mixed duopoly, we show that in the contexts of both a price competition and a quantity competition, the owners of both firms employ more aggressive managers. In particular, in the result obtained in the price competition, the attitude of the manager employed by the owner of the private firm reverses to that obtained in the case of classical strategic delegation works.

\section{Keywords}

\section{Strategic Delegation, Biased Expectations, Aggressiveness, Product Market Competition}

\section{Introduction}

As shown in Kaplan et al. [1], a candidate's aggressiveness seems to be an important characteristic in the hiring choice for CEO positions within firms. More precisely, Kaplan et al. [1] found empirical evidence that firms tend to systematically hire managers whose attitudes are relatively aggressive in the market ${ }^{1}$. Following the empirical works of Kaplan et al. [1], in their recent works, Englmaier and Reisinger [3] provided the rationale for this fact in the context of strategic delegation literature by adopting a new approach. In the context of a standard mixed duopoly composed of one social welfare-maximizing public firm and one absolute profit-maximizing firm, the aim of this paper is to provide a theoretical explanation for the fact that in the real world economy, each firm's owner tends to systematically hire a manager who is relatively aggressive through strategic managerial delegation. More concretely, on the basis of the approach presented in Englmaier and Reisinger [3], we

\footnotetext{
${ }^{1}$ Svenson [2] showed substantial further evidence for the existence of persistent biases in expectations.
} 
consider a model in which, before engaging the price-setting competition and the quantity-setting competition in the above mixed duopoly, each firm's owner hires a manager whose type corresponds to her/his potentially biased expectation on market profitability.

In the context of mixed oligopoly, Barros [4] and White [5] are seminal works in the field of the strategic managerial delegation. Barros [4] emphasized the strategic managerial delegation aspects of managerial incentive contracts under asymmetric information, focusing on their usefulness in alleviating principle/agent issues, whereas White [5] focused on the strategic benefits of such arrangements in situations of complete information within both the public firm and the private firm. Barros [4] and White [5] both investigated situations wherein both the public and private firms produce homogeneous goods. Moreover, in a mixed duopoly with differentiated goods, Nakamura and Inoue [6] and Nakamura and Inoue [7] explored the endogenous timing issue by using the observable delay game introduced in Hamilton and Slutsky [8] in the contexts of a quantity competition and a price competition, respectively. In particular, given that the simultaneous setting of the content of each firm's managerial delegation contract, that is, the timing of the delegation parameter of the manager provided by her/his owner is fixed, Nakamura and Inoue [6] and Nakamura and Inoue [7] considered the timing on the determination of her/his quantity and price levels, respectively. Subsequently, Bárcena-Ruiz [9] focused on the endogenous timing issue of the determination of each firm's delegation parameter when the price-setting of each firm is fixed as the simultaneous market ${ }^{2}$. Departing from the classical approach introduced in Fershtman and Judd [11], Sklivas [12], and Vickers [13], to explain each firm's manager's potentially biased expectation on market profitability, in this paper, we apply the approach presented by Englmaier and Reisinger [3] to the context of a mixed duopoly composed of one public firm and one private firm. Then, we investigate whether aggressive or conservative managers should be employed within both the public firm and the private firm relative to the case that the former firm is a sole social welfare-maximizer while the latter firm is a sole profit-maximizer.

In this paper, in the mixed duopoly, we show that in both the price competition and quantity competition, the owners of both the public firm and private firm employ more aggressive managers than in the case of absolute profit-maximizers. In particular, the result obtained in the price competition is strikingly different from that obtained in Nakamura and Inoue [7] and Bárcena-Ruiz [9], which considered the price-setting mixed duopoly following the approach of Fershtman and Judd [11], Sklivas [12], and Vickers [13]. More precisely, in this paper, in the price competition in a mixed duopoly, we find that not only the owner of the public firm but also the owner of the private firm employ more aggressive managers. In the price-setting mixed duopoly, employing a conservative manager in the private firm yields the excess intercept of the market share of that firm by the aggressive manager of the public firm, implying that the owner of the private firm should employ an aggressive manager. In the case of the quantity-setting mixed duopolistic market, the aggressiveness of the managers employed by both firms obtained in this paper is the same as that obtained in the existing works that follow Fershtman and Judd [11], Sklivas [12], and Vickers [13] including Nakamura and Inoue [6] ${ }^{3}$.

The remainder of this paper is organized as follows. In Section 2, we build the basic model employed in this paper. In Section 3, we attempt to derive the Nash equilibrium market outcomes in the context of the price-setting competition. In Section 4, we attempt to derive the Nash equilibrium market outcomes in the context of the quantity-setting competition. Section 5 concludes with several remarks.

\section{Model}

We consider a mixed duopolistic market composed of one social welfare-maximizing public firm (firm 0 ) and one absolute profit-maximizing private firm, (firm 1). The basic structure of the model follows a standard product differentiation model as in Dixit [14] and Singh [15]. Thus, firms 0 and 1 face the following inverse and ordinary demand functions:

$$
\begin{cases}p_{i}=a-q_{i}-b q_{j}, & \text { [quantity competition], } \\ q_{i}=\left[a(1-b)-p_{i}+b p_{j}\right] /\left(1-b^{2}\right), & \text { [price competition], } i, j=0,1 ; i \neq j,\end{cases}
$$

\footnotetext{
${ }^{2}$ As another line of strategic managerial delegation in mixed oligopoly, Bárcena-Ruiz [10] analyzed the decisions of both the public firm and the private firm regarding whether or not to hire managers when they engage in price competition.

${ }^{3}$ The result that the aggressive managers can hired not only within the private firm but also within the private firm is strongly associated with the fact that the aggressive management reforms of local public firms proceed in order to get out of the hole in the red within them, in particular in the industries of water and sewage line and so on in Japan.
} 
where $a>0$ and $b \in(0,1)$ are the demand parameters, $q_{i}$ is the quantity level of good $i$, and $p_{i}$ is its price level, $(i, j=0,1)^{4}$. These inverse and ordinary demand functions result from the following representative consumer's utility:

$$
U\left(q_{0}, q_{1}\right)=a\left(q_{0}+q_{1}\right)-\frac{q_{0}^{2}+2 b q_{0} q_{1}+q_{1}^{2}}{2}+m
$$

Following Englmaier and Reisinger [3], we model the situation in which each firm's managers are potentially biased in the sense that they evaluate the size of the market, $a$, incorrectly. This is expressed in the following way: if the owner of firm $i$ in the first stage hires a manager of type $k_{i}$, this manager believes that the inverse and ordinary demand functions of firm $i$ are given by

$$
\begin{cases}p_{i}\left(q_{i}, q_{j}\right)=a k_{i}-q_{i}-b q_{j}, & \text { [quantity competition], } \\ q_{i}\left(p_{i}, p_{j}\right)=\left(a k_{i}-a b k_{j}-p_{i}+b p_{j}\right) /\left(1-b^{2}\right), & \text { [price competition], } \quad i=0,1, \quad i \neq j .\end{cases}
$$

Note that $k_{i}<1$ indicates that such a manager considers the market size to be too small, whereas $k_{i}>1$ indicates that such a manager considers the market size to be too large; both are incorrect ${ }^{5}$. The marginal costs of production of firms 0 and 1 are commonly assumed to be $c$. The profit function of firm $i$ is given by $\pi_{i}=\left(p_{i}-c\right) q_{i}, \quad(i=0,1)^{6}$. The consumer surplus is represented by using the representative consumer utility in Equation (1) as follows: $C S=U\left(q_{0}, q_{1}\right)-p_{0} q_{0}-p_{1} q_{1}$. The producer surplus is given by the sum of the profits of both firms 0 and $1, \pi_{0}$ and $\pi_{1}$. Finally, we define social welfare as the sum of the consumer surplus and the producer surplus.

We investigate the game with the following orders: In the first stage, firm $i$ 's owner determines her/his optimal manager with type $k_{i}{ }^{7}$. In the second stage, the hired managers of firms 0 and 1 compete in the market by maximizing the objective functions of firms 0 and 1 with respect to $p_{0}\left(q_{0}\right)$ and $p_{1}\left(q_{1}\right)$, respectively.

Similar to Englmaier and Reisinger [3], the assumption on $k_{i}$ is important. This assumption is related to the expectation that firm $i$ 's manager holds about the demand intercept of firm $j,(i, j=0,1 ; i \neq j)$. Since the type of the rival manager is observable to firm $i$ 's manager, it is natural that his belief about firm $j$ 's intercept is related to $k_{j}{ }^{8}$. In this paper, to simplify the exposition, we assume that the expectation of firm $i$ 's manager about firm $j$ 's intercept is the same as that of manager $j: k_{j} a,(i, j=0,1 ; i \neq j)$.

\section{Price-Setting Competition}

In this section, we consider the price-setting competition by using backward induction in order to derive the subgame perfect Nash equilibrium (SPNE), and thus we start to conduct the analysis of the second stage. In the second stage, the manager of firm $i$ maximizes the following profits of firm $i$ with respect to $p_{i}$ :

$$
V_{i}^{m}\left(p_{i}, p_{j}, k_{i}, k_{j}\right)=\frac{\left(p_{i}-c\right)\left(a k_{i}-a b k_{j}-p_{i}+b p_{j}\right)}{1-b^{2}}, \quad i, j=0,1 ; i \neq j
$$

Given the values of both $k_{i}$ and $k_{j}$, we have the following the Nash equilibrium price level of firm $i$ in the price-setting stage:

$$
p_{i}\left(k_{i}, k_{j}\right)=\frac{a\left[\left(2-b^{2}\right) k_{i}-b k_{j}\right]+(2-b) c}{4-b^{2}}
$$

\footnotetext{
${ }^{4} b \in(0,1)$ indicates that the relation between the goods produced by firms 0 and 1 is substitutable. We omit the trivial case wherein $b=0$, which implies that the goods produced of the firms are independent of each other.

${ }^{5}$ Firm $i$ 's manager is not biased in the case wherein $k_{i}=1$, $(i=0,1)$.

${ }^{6}$ We assume that $a>c \geq 0$ in order to ensure the non-negativity of all equilibrium outcomes.

${ }^{7}$ Although one wonders whether or not firm $i$ 's owner can choose the type of her manager, the level of $k_{i}$, this is justified as follows: In this paper, we assume that each owner selects a manager from a pool containing sufficiently differentiated-typed managers tying the compensations to some sort of combination of her own profit. Moreover, we assume that the effect on each firm's profit of tying managerial compensation to firm performance is negligible.

${ }^{8}$ As indicated in Englmaier and Reisinger [3], the type of manager is observable for both firms 0 and 1 . Since the identity of the manager of each firm is public information who is the manager of each firm, the type of manager is also observable to the manager of the rival firm, which implies that it is important in the market competition stage.
} 


$$
q_{i}\left(k_{i}, k_{j}\right)=\frac{a\left[2\left(2-k_{i}\right)-b\left(4-3 k_{j}\right)-b^{2}+b^{3}\left(1-k_{j}\right)\right]-c\left(2-b-b^{2}\right)}{4-5 b^{2}+b^{4}}, \quad i, j=0,1 ;, \quad i \neq j
$$

From easy calculations we obtain the following results:

$$
\left\{\begin{array}{l}
\partial p_{i}\left(k_{i}, k_{j}\right) / \partial k_{i}=a\left(2-b^{2}\right) /\left(4-b^{2}\right)>0, \\
\partial p_{i}\left(k_{i}, k_{j}\right) / \partial k_{j}=-a b /\left(4-b^{2}\right)<0, \quad i, j=0,1 ; \quad i \neq j .
\end{array}\right.
$$

Thus, the optimal price level of firm $i$ increases in $k_{i}$ and decreases in $k_{j},(i, j=0,1 ; i \neq j)$. These properties are the same as those obtained in the private duopoly investigated in Englmaier and Reisinger [3], since the analysis conducted until the second stage under backward induction is the same as that in Englmaier and Reisinger [3]. ${ }^{9}$

Next, we consider the analysis of the first stage, the determination of $k_{0}$ and $k_{1}$. The following objective functions of firms 0 and 1 in the first stage are given as follows:

$$
\begin{aligned}
& V_{0}^{o}\left(k_{0}, k_{1}\right)=W\left(k_{0}, k_{1}\right)=C S\left(k_{0}, k_{1}\right)+\pi_{0}^{o}\left(k_{0}, k_{1}\right)+\pi_{1}^{o}\left(k_{0}, k_{1}\right) \\
& =\frac{1}{2}\left[q_{0}^{2}\left(k_{0}, k_{1}\right)+2 b q_{0}\left(k_{0}, k_{1}\right) q_{1}\left(k_{0}, k_{1}\right)+q_{1}^{2}\left(k_{0}, k_{1}\right)\right]+m \\
& +\frac{\left[p_{0}\left(k_{0}, k_{1}\right)-c\right]\left[a(1-b)-p_{0}\left(k_{0}, k_{1}\right)+b p_{1}\left(k_{0}, k_{1}\right)\right]}{1-b^{2}} \\
& +\frac{\left[p_{1}\left(k_{0}, k_{1}\right)-c\right]\left[a(1-b)-p_{1}\left(k_{0}, k_{1}\right)+b p_{0}\left(k_{0}, k_{1}\right)\right]}{1-b^{2}}, \\
& V_{1}^{o}\left(k_{0}, k_{1}\right)=\pi_{1}^{o}\left(k_{0}, k_{1}\right)=\frac{\left[p_{1}\left(k_{0}, k_{1}\right)-c\right]\left[a(1-b)-p_{1}\left(k_{0}, k_{1}\right)+b p_{0}\left(k_{0}, k_{1}\right)\right]}{1-b^{2}},
\end{aligned}
$$

where the values of $p_{i}\left(k_{i}, k_{j}\right), p_{j}\left(k_{i}, k_{j}\right), q_{i}\left(k_{i}, k_{j}\right)$, and $q_{j}\left(k_{i}, k_{j}\right)$ are denoted in Equations (2) and (3), $(i=0,1 ; i \neq j)$.

The owners of firms 0 and 1 maximize social welfare and their absolute profit with respect to $k_{0}$ and $k_{1}$, respectively. By solving the first-order condition for the owners in the first stage, we obtain the following: ${ }^{10}$

$$
\begin{aligned}
& \frac{\partial V_{0}^{o}\left(k_{0}, k_{1}\right)}{\partial k_{0}}=\frac{a\left\{(1-b)^{3}(2+b)^{2} c-a\left[\left(4+b^{2}-b^{4}\right) k_{0}-b\left(8-5 b^{2}+b^{4}\right) k_{1}\right]\right\}}{\left(4-b^{2}\right)^{2}\left(1-b^{2}\right)}=0 \\
& \Leftrightarrow k_{0}\left(k_{1}\right)=\frac{a b\left(8-5 b^{2}+b^{4}\right) k_{1}+c(1-b)^{3}(2+b)^{2}}{a\left(4+b^{2}-b^{4}\right)}, \\
& \frac{\partial V_{1}^{o}\left(k_{0}, k_{1}\right)}{\partial k_{1}} \\
& \quad \frac{a\left\{a\left[8+b^{4}+b^{3}\left(6-5 k_{0}\right)-8 b\left(1-k_{0}\right)-b^{5}\left(1-k_{0}\right)-8 k_{1}-b^{2}\left(6-4 k_{1}\right)-b^{5}\left(1-k_{0}\right)\right]+b^{2} c\left(2 b-b^{2}\right)\right\}}{\left(4-b^{2}\right)^{2}\left(1-b^{2}\right)}=0, \\
& \Leftrightarrow k_{1}\left(k_{0}\right)=\frac{a\left[8-6 b^{2}+b^{4}+b^{3}\left(6-5 k_{0}\right)-8 b\left(1-k_{0}\right)-b^{5}\left(1-k_{0}\right)\right]+b^{2} c\left(2-b-b^{2}\right)}{4 a\left(2-b^{2}\right)},
\end{aligned}
$$

yielding

\footnotetext{
${ }_{9}^{9}$ As indicated in Englmaier and Reisinger [3], the manager of firm $i$ behaves less aggressively in the price-setting market such that her/his higher price becomes optimal, as the value of $k_{i}$ increases, $(i, j=0,1 ; i \neq j)$. On the other hand, as $k_{j}$ becomes larger, the manager of firm $j$ sets her/his larger quantity, $q_{j}$, such that the manager of firm $i$ decreases the price level, $p_{i}$.

${ }^{10}$ The second-order conditions are satisfied, and hence there is a unique equilibrium in this model.
} 


$$
\begin{aligned}
& k_{0}^{p p}=\frac{a b\left(16-18 b^{2}+7 b^{4}-b^{6}\right)+c\left(8-8 b-8 b^{2}+10 b^{3}+5 b^{4}-2 b^{5}-b^{6}\right)}{a(1+b)\left(8-8 b^{2}+5 b^{4}-b^{6}\right)}, \\
& k_{1}^{p p}=\frac{a\left(8-2 b^{2}-3 b^{4}+b^{6}\right)+b c\left(8-6 b-8 b^{2}+8 b^{3}+5 b^{4}-2 b^{5}-b^{6}\right)}{a(1+b)\left(8-8 b^{2}+5 b^{4}-b^{6}\right)} .
\end{aligned}
$$

Similar to Englmaier and Reisinger [3], we check whether the owners of firms 0 and 1 hire aggressive or conservative managers. We obtain the following result:

$$
\begin{aligned}
& k_{0}^{p p}-1=-\frac{\left(8-8 b-8 b^{2}+10 b^{3}+5 b^{4}-2 b^{5}-b^{6}\right)(a-c)}{a(1+b)\left(8-8 b^{2}+5 b^{4}-b^{6}\right)}<0, \\
& k_{1}^{p p}-1=-\frac{b\left(8-6 b-8 b^{2}+8 b^{3}+5 b^{4}-2 b^{5}-b^{6}\right)(a-c)}{a(1+b)\left(8-8 b^{2}+5 b^{4}-b^{6}\right)}<0 .
\end{aligned}
$$

Summing the above result, we obtain the following result:

Proposition 1. In the game with a price-setting mixed duopoly, the owners of both public firm 0 and private firm 1 hire aggressive managers, $k_{0}<1$ and $k_{1}<1$.

The intuition behind the results described in Proposition 1 is as follows: the owner of public firm 0 takes the consumer surplus into account, and thus s/he makes her/his manager behave aggressively in the market by decreasing the value of $k_{0}$. Furthermore, from easy calculations, we obtain the following result:

$$
\left\{\begin{array}{l}
\mathrm{d} k_{0}\left(k_{1}\right) / \mathrm{d} k_{1}=b\left(8-5 b^{2}+b^{4}\right) /\left(4+b^{2}-b^{4}\right)>0, \\
\mathrm{~d} k_{1}\left(k_{0}\right) / \mathrm{d} k_{0}=b\left(8-5 b^{2}+b^{4}\right) /\left(8-4 b^{2}\right)>0 .
\end{array}\right.
$$

Thus, since the strategic relation between $k_{0}$ and $k_{1}$ is a strategic complement, a low level of $k_{0}$ induces a lower level of $k_{1}$. Englmaier and Reisinger [3] showed that even in the private duopoly wherein the two private firms maximize their absolute profits rather than social welfare, the owner of firm $i$ employs a manager with the lower level of $k_{i},(i=0,1)$. In addition to the strategic complementarity between $k_{0}$ and $k_{1}$, the aggressiveness of the manager of public firm 0 makes the manager of private firm 1 behave aggressively in the market as well, $k_{i}<0,(i=0,1)$.

Thus, the result obtained in Propostioin 1 is similar to that obtained in the standard private duopoly explored in Englmaier and Reisinger [3]. Moreover, the aggressiveness of the manager employed by private firm 1 increases because of the presence of the public firm, as compared to the case wherein the opponent firm is also a private firm. On the other hand, in the price-setting mixed duopoly, the result that an aggressive manager is employed by the private firm in the price competition, which is strikingly different from Nakamura and Inoue [7] and Bárcena-Ruiz [9] in which the approach of Fershtman and Judd [11], Sklivas [12], and Vickers [13] was adopted.

\section{Quantity-Setting Competition}

In this section, we consider the quantity-setting competition by conducting a similar analysis to that of the pricesetting competition. From the same processes presented in Section 3, we obtain the following Nash equilibrium quantities in the second stage:

$$
q_{i}\left(k_{i}, k_{j}\right)=\frac{2 a k_{i}-a b k_{j}-c(2-b)}{4-b^{2}}, \quad i, j=0,1 ; i \neq j
$$

Furthermore, from easy calculations, we obtain the following result:

$$
\left\{\begin{array}{l}
\partial q_{i}\left(k_{i}, k_{j}\right) / \partial k_{i}=2 a /\left(4-b^{2}\right)>0, \\
\partial q_{j}\left(k_{i}, k_{j}\right) / \partial k_{j}=-a b /\left(4-b^{2}\right)<0 .
\end{array}\right.
$$

Thus, the owner of firm $i$ employs an aggressive manager as the value of $k_{i}$ increases, as shown in Englmaier 
and Reisinger [3], whereas $q_{i}$ is negatively associated with the value of the opponent firm’s manager, $k_{j}$, $(i, j=0,1 ; i \neq j)$. By adopting the Nash equilibrium outcomes in the second stage, we obtain the following expectations of the managers of firms 0 and 1 in the subgame perfect Nash equilibrium:

$$
\begin{aligned}
& k_{0}^{q q}=\frac{2 a\left(8-4 b-4 b^{2}+b^{3}\right)-c\left(8-8 b+2 b^{3}-b^{4}\right)}{a\left(8-8 b^{2}+b^{4}\right)}, \\
& k_{1}^{q q}=\frac{a\left(8-6 b^{2}-2 b^{3}+b^{4}\right)-2 c(1-b) b^{2}}{a\left(8-8 b^{2}+b^{4}\right)} .
\end{aligned}
$$

Furthermore, from easy calculations, we obtain the following result:

$$
\begin{aligned}
& k_{0}^{q q}-1=\frac{\left(8-8 b+2 b^{3}-b^{4}\right)(a-c)}{a\left(8-8 b^{2}+b^{4}\right)}>0, \\
& k_{1}^{q q}-1=\frac{2(1-b) b^{2}(a-c)}{a\left(8-8 b^{2}+b^{4}\right)}>0 .
\end{aligned}
$$

Furthermore, we have

$$
k_{0}^{q q}-k_{1}^{q q}=(2-b)^{2}\left(2-b^{2}\right)(a-c) / a\left(8-8 b^{2}+b^{4}\right)>0 .
$$

Summing up all the above results, we have the following proposition.

Proposition 2. Similar to the price-setting competition, in the game with a quantity-setting mixed duopoly wherein firm 0 maximizes social welfare and firm 1 maximizes its absolute profit, respectively, the owners of both firms hire aggressive managers, $k_{0}>1$ and $k_{1}>0,(i=0,1)$. Moreover, the owner of the public firm employs a manager who behaves more aggressively than the manager of the private firm.

The intuition behind the results described in Proposition 2 is given as follows: we find that in the first stage, the strategic relation between $k_{0}$ and $k_{1}$ is a strategic substitute from the following calculations:

$$
\left\{\begin{array}{l}
\mathrm{d} k_{0}\left(k_{1}\right) / \mathrm{d} k_{1}=-b^{3} /\left(4-3 b^{2}\right)<0, \\
\mathrm{~d} k_{1}\left(k_{0}\right) / \mathrm{d} k_{0}=-b^{3} / 4\left(2-b^{2}\right)<0 .
\end{array}\right.
$$

Similar to the price competition, in the quantity competition, the owner of public firm 0 employs a manager who becomes more aggressively in the market since that firm takes consumer surplus into account. On the other hand, if the owner of private firm 1 employs a manager with $k_{1} \leq 0$, firm 1 's market share becomes too small by yielding the higher level of $k_{0}$ because of the strategic substitutability between $k_{0}$ and $k_{1}$. This effect that the market share of firm 1 decreases dominates the effect that the profit of firm 1 increases through the higher level of $p_{1}$ by setting a lower level of $k_{1}$. Thus, the owners of both firms 0 and 1 employ aggressive managers with $k_{0}>1$ and $k_{1}>0$.

The results obtained in Proposition 2 are similar to those obtained in the works on strategic managerial delegation in a quantity-setting mixed duopoly, which includes Nakamura and Inoue [6] following Fershtman and Judd [11], Sklivas [12], and Vickers [13]. More precisely, in the context of classical strategic managerial delegation, in a quantity-setting mixed duopoly, the owners of both the public firm and the private firm choose more aggressive managers than in the case of sole absolute-maximizers. Moreover, the owner of the public firm employs a more aggressive manager than the owner of the private firm does.

\section{Concluding Remarks}

This paper explored the situation wherein it was possible for each firm's owner to hire a biased manager in a mixed duopoly composed of one social welfare-maximizing public firm and one absolute profit-maximizing private firm in the contexts of both a price competition and a quantity competition.

In this paper, we showed that in the contexts of both a price competition and a quantity competition in a mixed duopoly, the owners of both the public firm and the private firm hire aggressive managers. In particular, in a price-setting mixed duopolistic market, the owner of the private firm can employ an aggressive manager, 
which is strikingly different from the existing works on strategic managerial delegation in mixed oligopoly, which includes Nakamura and Inoue [7] and Bárcena-Ruiz [9] ${ }^{11}$.

Finally, we mention the open problems to be tackled in our future research. First, taking into account that firms' owners evaluate their managers not on the basis of their absolute profit, but on the basis of their relative profit, which is the weighted sum of their own absolute profit and the absolute profits of the opponent firms in the real world economy, we should address the situation wherein the owners of competing firms can hire biased managers with respect to the market size they face, and in which the objective functions of their managers are their relative profits. Second, in recent works on strategic managerial delegation, the results obtained in classical strategic delegation studies Fershtman and Judd [11], Sklivas [12], and Vickers [13] are reversed in several economic environments. For example, Hoernig [16] presented a worked-out example such that when the network effects where the surplus that a firm's client obtains increases directly with the number of other clients of this firm are sufficiently strong, in the price competition, firms' owners can hire more aggressive managers than in the case of the sole absolute-maximizer since owners' weights on profit in the fashion of Fershtman and Judd [11], Sklivas [12], and Vickers [13] can be strategic substitutes. As one of our future studies, we will consider the situation wherein firms' owners can employ a biased manager under the presence of such network effects and check whether firms' owners can employ aggressive or conservative managers under such an economic environment.

\section{Acknowledgements}

We would like to thank three anonymous referees for their helpful comments and suggestions. We are grateful for the financial support of KAKENHI (25870113). All remaining errors are our own.

\section{References}

[1] Kaplan, S.N., Klebanov, M.M. and Sorensen, M. (2012) Which CEO Characteristics and Abilities Matter? Journal of Finance, 67, 973-1007. http://dx.doi.org/10.1111/j.1540-6261.2012.01739.x

[2] Svenson, O. (1981) Are We All Less Risky and More Skillful than Our Fellow Drivers? Acta Psychologica, 47, 143-148. http://dx.doi.org/10.1016/0001-6918(81)90005-6

[3] Englmaier, F. and Reisinger, M. (2013) Biased Managers as Strategic Commitment. Managerial and Decision Economics, 35, 350-356.

[4] Barros, F. (1995) Incentive Schemes as Strategic Variables: An Application to a Mixed Duopoly. International Journal of Industrial Organization, 13, 373-386. http://dx.doi.org/10.1016/0167-7187(94)00461-A

[5] White, M.D. (2001) Managerial Incentives and the Decision to Hire Managers in Markets with Public and Private Firms. European Journal of Political Economy, 17, 877-896. http://dx.doi.org/10.1016/S0176-2680(01)00060-X

[6] Nakamura, Y. and Inoue, T. (2007) Endogenous Timing in a Mixed Duopoly: The Managerial Delegation Case. Economics Bulletin, 12, 1-7.

[7] Nakamura, Y. and Inoue, T. (2009) Endogenous Timing in a Mixed Duopoly: Price Competition with Managerial Delegation. Managerial and Decision Economics, 30, 325-333. http://dx.doi.org/10.1002/mde.1455

[8] Hamilton, J.H. and Slutsky, S.M. (1990) Endogenous Timing in Duopoly Games: Stackelberg or Cournot Equilibria. Games and Economic Behavior, 2, 29-46. http://dx.doi.org/10.1016/0899-8256(90)90012-J

[9] Bárcena-Ruiz, J.C. (2013) Endogenous Timing of Incentive Contracts in Mixed Markets under Bertrand Competition. Manchester School, 81, 340-355. http://dx.doi.org/10.1111/j.1467-9957.2011.02284.x

[10] Bárcena-Ruiz, J.C. (2007) The Decision to Hire Managers in Mixed Markets under Bertrand Competition. Japanese Economic Review, 60, 376-388. http://dx.doi.org/10.1111/j.1468-5876.2008.00455.x

[11] Fershtman, C. and Judd, K. (1987) Equilibrium Incentives in Oligopoly. American Economic Review, 77, 927-940.

[12] Sklivas, S.D. (1987) The Strategic Choice of Management Incentives. RAND Journal of Economics, 18, 452-458. http://dx.doi.org/10.2307/2555609

[13] Vickers, J. (1985) Delegation and the Theory of the Firm. Economic Journal, 95, 138-147.

\footnotetext{
${ }^{11}$ Note that in a price-setting mixed duopolistic market, when the value of $b$ is sufficiently high, that is, the relation between the goods produced by the firms is almost homogeneous, Nakamura and Inoue [7] and Barcena-Ruiz [9] showed that the owner of the public firm can employ a less aggressive manager than in the case of the sole absolute profit maximizer. Thus, in a price-setting mixed duopolistic market, the result on the aggressiveness of the manager of the public firm which was obtained in this paper is reversed to that obtained in Nakamura and Inoue [7] and Barcena-Ruiz [9], which follow Fershtman and Judd [11], Sklivas [12], and Vickers [13].
} 
http://dx.doi.org/10.2307/2232877

[14] Dixit, A. (1979) A Model of Duopoly Suggesting a Theory of Entry Barriers. Bell Journal of Economics, 10, 20-32. http://dx.doi.org/10.2307/3003317

[15] Singh, N. and Vives, X. (1984) Price and Quantity Competition in a Differentiated Duopoly. RAND Journal of Economics, 15, 546-554. http://dx.doi.org/10.2307/2555525

[16] Hoernig, S. (2012) Strategic Delegation under Price Competition and Network Effects. Economics Letters, 117, 487489. http://dx.doi.org/10.1016/j.econlet.2012.06.045 
Scientific Research Publishing (SCIRP) is one of the largest Open Access journal publishers. It is currently publishing more than 200 open access, online, peer-reviewed journals covering a wide range of academic disciplines. SCIRP serves the worldwide academic communities and contributes to the progress and application of science with its publication.

Other selected journals from SCIRP are listed as below. Submit your manuscript to us via either submit@scirp.org or Online Submission Portal.
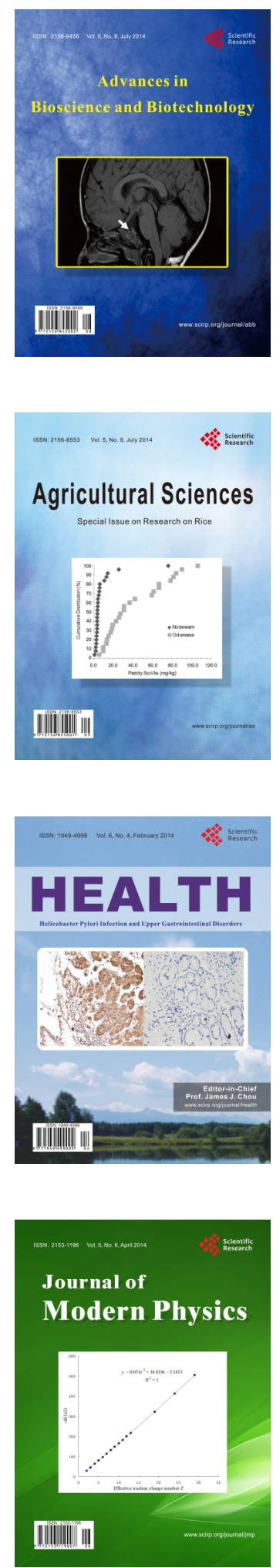
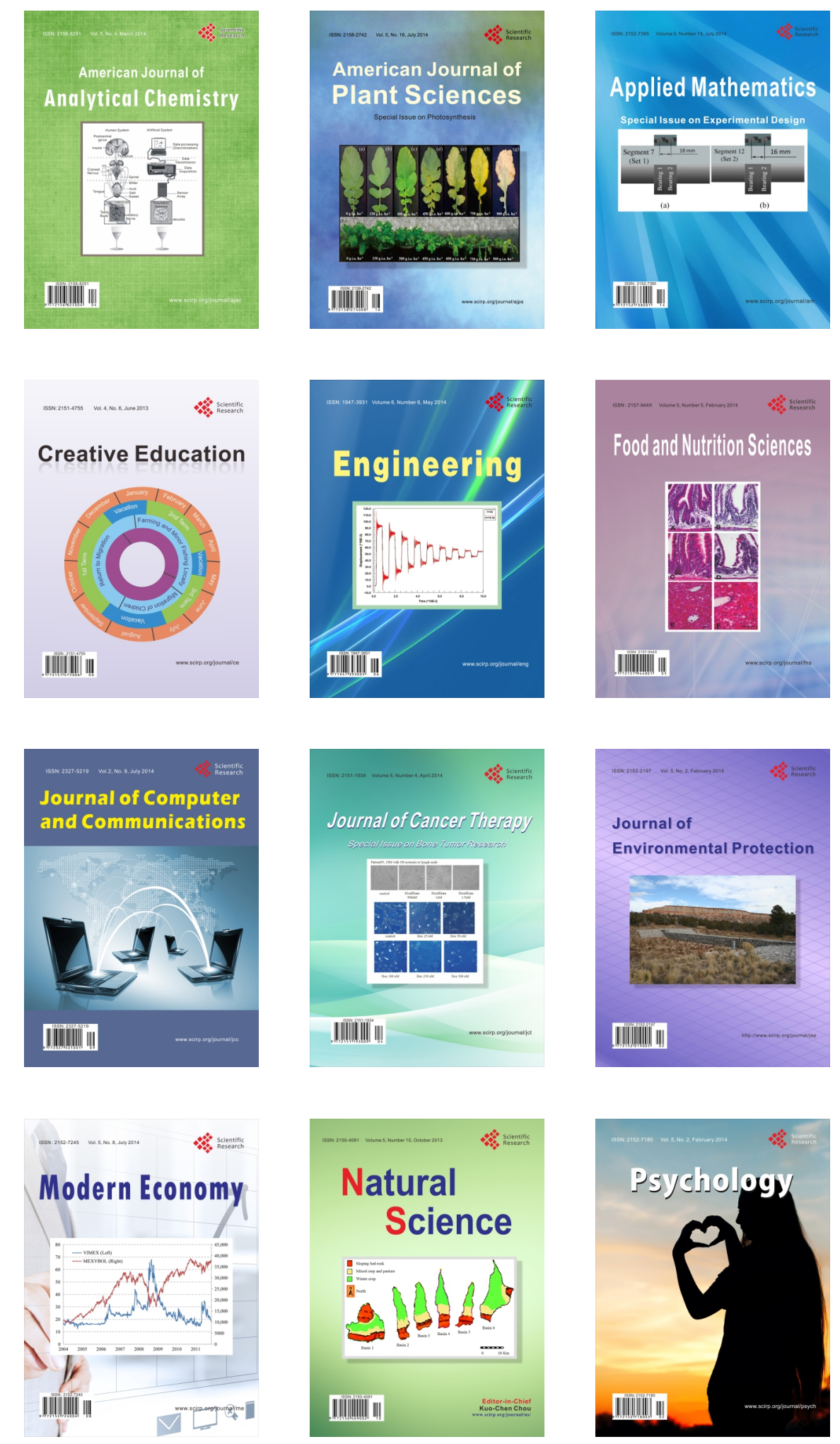